\title{
Current Information Technology Needs of Small to Medium Sized Apparel Manufacturers and Contractors
}

\author{
C. Wimple \\ E. Vosti
}

November 1997

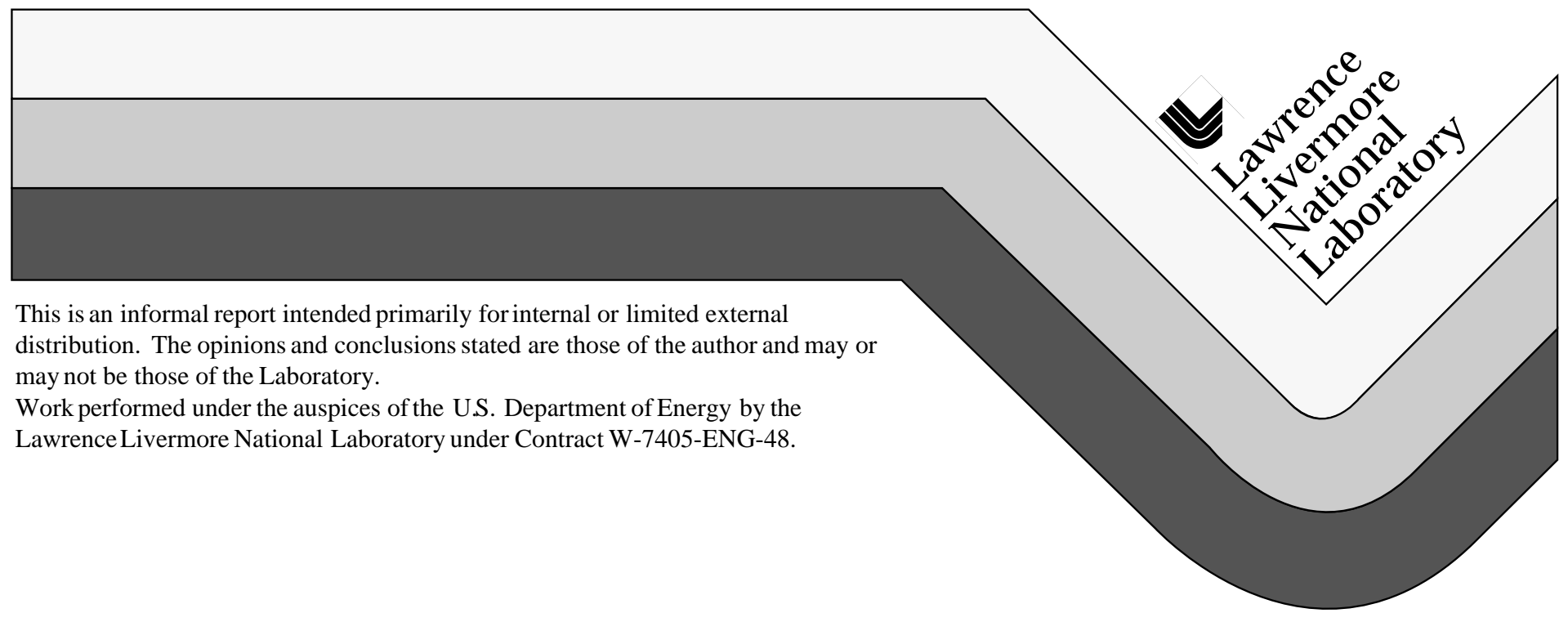




\section{DISCLAIMER}

This document was prepared as an account of work sponsored by an agency of the United States Government. Neither the United States Government nor the University of California nor any of their employees, makes any warranty, express or implied, or assumes any legal liability or responsibility for the accuracy, completeness, or usefulness of any information, apparatus, product, or process disclosed, or represents that its use would not infringe privately owned rights. Reference herein to any specific commercial product, process, or service by trade name, trademark, manufacturer, or otherwise, does not necessarily constitute or imply its endorsement, recommendation, or favoring by the United States Government or the University of California. The views and opinions of authors expressed herein do not necessarily state or reflect those of the United States Government or the University of California, and shall not be used for advertising or product endorsement purposes.

This report has been reproduced directly from the best available copy.

Available to DOE and DOE contractors from the Office of Scientific and Technical Information

P.O. Box 62, Oak Ridge, TN 37831

Prices available from (615) 576-8401, FTS 626-8401

Available to the public from the

National Technical Information Service

U.S. Department of Commerce 5285 Port Royal Rd.,

Springfield, VA 22161 


\section{Demand Activated Manufacturing Architecture}

\section{Current Information Technology Needs of Small to Medium Sized Apparel Manufacturers and Contractors}

November 1997

Version 1.0 
Demand Activated Manufacturing Architecture

SME Report

Connectivity and Infrastructure

Version 1.0 


\section{Acknowledgments}

We would like to acknowledge Sue Strickland and Mike Todaro of the American Apparel Producers' Network (formerly American Apparel Contractor's Association), Al Howell of the Southeastern Apparel Manufacturers and Suppliers Association, and Leonard Brewington of Milliken \& Company for helping us make contact with the companies represented in this report. In addition, we would like to acknowledge Bill Grimmell, Oak Ridge National Laboratory, for his participation in some of these visits and support of this effort. We would also like to acknowledge the following representatives from each company we visited for providing the information presented in this case study:

\begin{tabular}{|l|l|}
\hline Company & Contact \\
\hline A\&Z Industries, Ltd & Antoine J. ElChaar, President \& CEO \\
\hline Ashmore Sportswear & $\begin{array}{l}\text { Dennis H. Ashcroft, Vice- } \\
\text { President/Marketing } \\
\text { Selina Ashcroft, Sales \& Customer Service } \\
\text { Manager }\end{array}$ \\
\hline Craig Industries & $\begin{array}{l}\text { Larry Crolley } \\
\text { Ronnie Nixon } \\
\text { Debra Reynolds }\end{array}$ \\
\hline Encore Textiles, Inc. & $\begin{array}{l}\text { Daniel E. Bulluck, President and CEO } \\
\text { Terry Bulluck }\end{array}$ \\
\hline Granite Knitwear, Inc. & Michael R. Jones, President \\
\hline Hamrick Industries & Michael Hamrick \\
\hline Hemingway Apparel Inc. & Jack L. Marsh, CEO \\
\hline Lebanon Apparel & $\begin{array}{l}\text { Jeoff Bodenhorst, President } \\
\text { Marc Camnitz, Executive Vice President } \\
\text { Dan Vipperman, Vice President Operations } \\
\text { for Lebanon Plant }\end{array}$ \\
\hline Loungewear Manufacturing Corp. & $\begin{array}{l}\text { David Miller, President } \\
\text { Larry Miller, Vice President }\end{array}$ \\
\hline Lynn Manufacturing, Division of Courtland & DavidCaldwell \\
\hline Pattern Design Unlimited, Inc. & Gale Zorian, Vice-President \\
\hline Swansea Manufacturing Co. & Harvey Hellman \\
\hline The KYM Company & Mark C. Kapiloff, President \\
\hline Virginia Apparel Corporation & Thomas W. Mason, President \\
\hline &
\end{tabular}


Demand Activated Manufacturing Architecture

SME Report

Connectivity and Infrastructure

Version 1.0 


\section{Table of Contents}

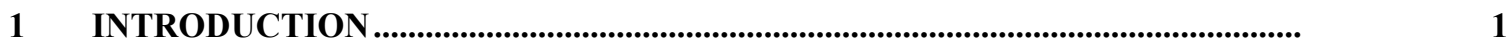

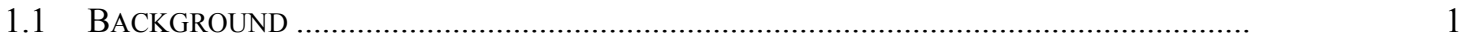

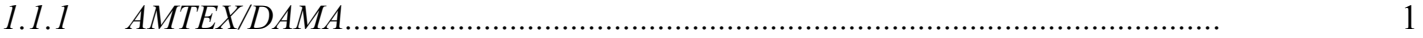

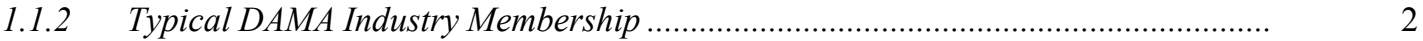

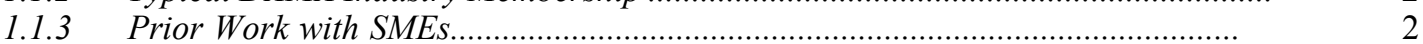

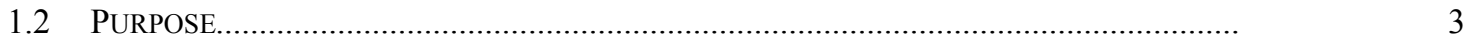

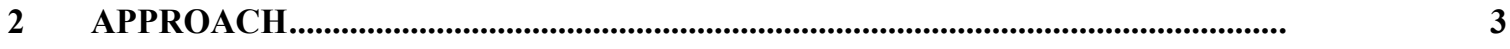

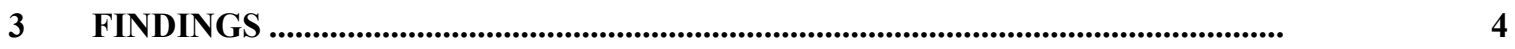

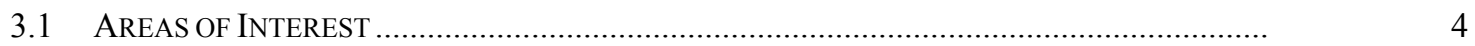

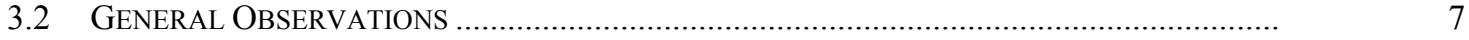

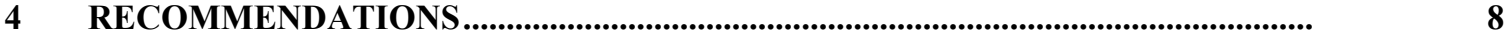

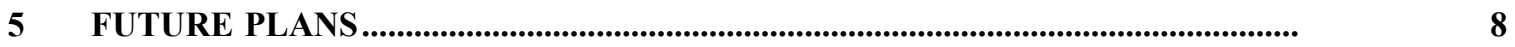

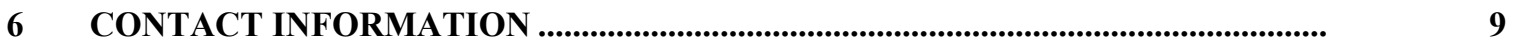

7 APPENDIX A - US SMALL BUSINESS ADMINISTRATION (SBA) DEFINITION OF

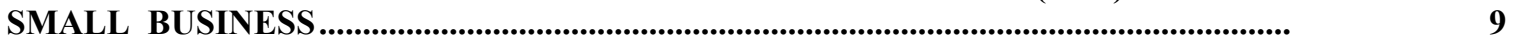

8 APPENDIX B - ORGANIZATION FOR ECONOMIC COOPERATION AND DEVELOPMENT (OECD) DEFINITION OF SME ..............................................................

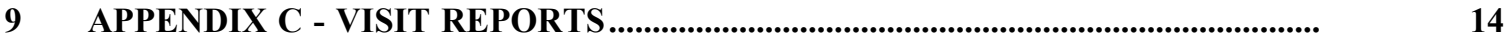


Demand Activated Manufacturing Architecture

SME Report

Connectivity and Infrastructure

Version 1.0

1 


\section{Introduction}

This report documents recent efforts of the American Textile Partnership (AMTEX ${ }^{\mathrm{TM}}$ ) Demand Activated Manufacturing Architecture (DAMA) Project to address needs that are characteristic of small ${ }^{1}$ to medium sized ${ }^{2}$ apparel manufacturers and contractors. Background on the AMTEX/DAMA project and objectives for this specific effort are discussed below. Section 2 Approach outlines the approach used to gather information about current needs, and Section 3 Findings identifies relevant findings and presents a brief analysis of the information gathered. Section 4 Recommendations offers recommendations based on the analysis, and Section $5 \quad$ Future Plans suggests plans for follow-on work to be conducted by DAMA. "Appendix C - Visit Reports" contains the data on which the analysis presented in "Section 3 Findings 3 Findings" is based.

\subsection{Background}

\subsubsection{AMTEX/DAMA}

The American Textile Partnership (AMTEX ${ }^{\mathrm{TM}}$ ) is a partnership, established in 1993, between the U.S. Department of Energy (DOE) and the U.S. Integrated Textile Complex (ITC). The AMTEX goal is to use DOE technologies to improve the industry's competitiveness in the world market. The flagship project within AMTEX is called Demand Activated Manufacturing Architecture (DAMA). This project focuses on applying information technology to improve the efficiency of the textile supply chain by reducing lead times and inventories.

The impetus for the DAMA Project is the U. S. ITC's domestic loss of marketshare. During the past 26 years, employment in the textile and apparel industries has declined from over 2.3 million in 1970 to 1.4 million today. This $30 \%$ decline is distinct when noting that the decrease among other manufacturing sectors has been about $1 \%$, and that overall, the rise in employment among all workers over the same period has been about $58 \%{ }^{3}$

Figure Error! Style not defined.-Error! Bookmark not defined. highlights that during the period of 1980 to 1996, over 622,000 textile and apparel manufacturing jobs were lost as a direct result of foreign imports. During this period, the U.S. marketshare went from $83 \%$ to $51 \%$ in the U. S. marketplace. Furthermore, U. S. ITC job losses appear to be increasing, as 186,000 jobs were lost between 1994 and 1996. The associated shrinking marketshare has caused follow-on losses across the industry because of interdependencies

${ }^{1} 7$ Appendix A - US Small Business Administration (SBA) Definition of Small Business gives the US Government's Small Business Administration's current guidelines for qualifying as a small business.

${ }^{2}$ Appendix B - OECD Definition of SME gives the Organization for Economic Cooperation and Development's definition of a Small and Medium-sized Enterprise

${ }^{3}$ Source: DAMA FY98 Project Plan, DAMA-I-8 97, September, 1997, Version 1.0 
among the industry's production components (fiber, textile, manufactured goods, and apparel) and equipment suppliers.

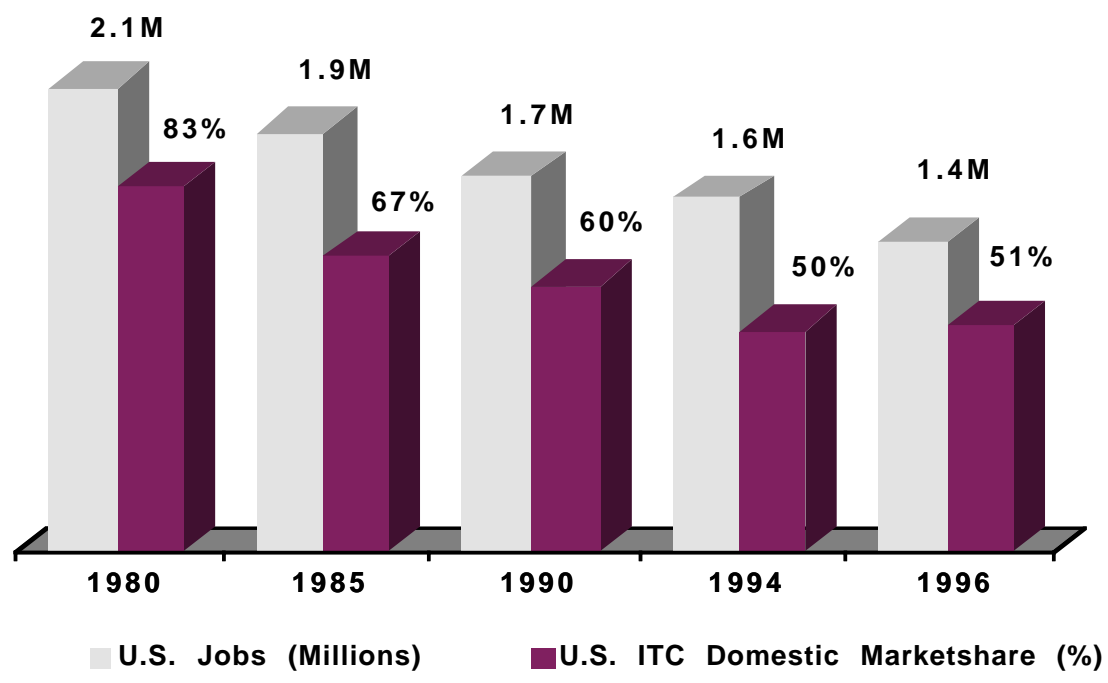

\section{Source: ATMI and Bureau of Labor Statistics Figure Error! Style not defined.-Error! Bookmark not defined. U.S. ITC Job and Marketshare Trends}

The labor-intensive U.S. apparel sector (accounting for about 21,450 small- and mediumsized companies) lags behind the same sector in developing countries in output per unit of costs. There is an 8:1 differential in total wages between those of the U. S. and Mexico, and a 4:1 differential in total wages between the U. S. and the average wage in the Pacific Rim countries. This differential in manufacturing costs has led to the majority of job and domestic marketshare losses. It is through the strength and interactions of other U. S. ITC sectors that the DAMA Project can build on improving the productivity of the apparel sector.

\subsubsection{Typical DAMA Industry Membership} Currently, 32 of the nation's leading companies are committed partners in DAMA. In addition to the traditional formal U.S. ITC supply chain of fiber producers, textile mills, apparel manufacturers, and retailers, DAMA partner companies include technological organizations whose contribution will be vital to the successful implementation of the results of work in the national laboratories. A typical DAMA partner company is not classified as small or medium sized.

\subsubsection{Prior Work with SMEs}

A meeting of representatives from several US ITC Small and Medium-sized Enterprises (SMEs) took place in Cary, North Carolina, on May 1 and 2, 1995. The purpose of the meeting was to obtain input from SMEs for the DAMA project in the specific areas of 
communication and information systems. DAMA funding uncertainties surfaced immediately following this meeting, causing the project to redirect its efforts. While a report documenting the events of the meeting was published, no specific conclusions or recommendations for follow-on activities were included.

\subsection{Purpose}

Crucial to the success of the DAMA project is representation from and participation of all sizes and types of companies, ranging from Fortune 500 size companies to SMEs. From the beginning, DAMA has had as part of its charter to understand and address the issues of SMEs in the U.S. ITC. This report, the activities that went into the collection of its information, and future activities that will follow, represent DAMA's focused effort to:

1. identify and understand the information technology needs of this vital sector of the ITC, and

2. apply DAMA expertise and technology to benefit these and similar companies.

\section{Approach}

As part of this effort to understand and address the issues of SMEs, representatives from DAMA industry partners and the DOE Laboratories visited fourteen SME companies during June, July, and August. The purpose of these visits was to gain an understanding of each company's business and to gather input from the leaders of these companies on needs that DAMA might help address.

First, the leadership of two prominent apparel manufacturers and contractors organizations, American Apparel Producers' Network (AAPN), formerly American Apparel Contractor's Association (AACA) and Southeastern Apparel Manufacturers \& Suppliers Association (SEAMS) were approached to apprise them of DAMA's efforts and its intentions to approach particular SMEs. At these meetings, the organizations' leadership worked with DAMA representatives to identify specific companies as candidates to be included in this study. The candidate companies were grouped by organization and by geographic location. A small number of identified companies were not visited due to scheduling or travel difficulties. Given that the DAMA DOE representatives who would visit these companies, in most cases, were traveling from the West Coast, significant effort was made to arrange visits to as many companies as possible in a given week, in order to reduce travel costs.

Visits occurred in three separate weeks. The first set of visits occurred the week of June 23, 1997 and focused on AAPN (AACA) members that could be easily reached in the Atlanta and Charlotte areas. The second set of visits was conducted the week of July 21, 1997 to AAPN members who were in various locations in Pennsylvania and Virginia. The third and final set of visits took place the week of August 25, 1997 and focused on 
members of SEAMS and included one company in Virginia, and several companies in South Carolina.

Despite the cost of conducting a number of visits over an extended period of time, this approach of directly visiting targeted companies was considered the most effective from the perspective of those DAMA participants who conducted the visits. This approach offered the following benefits:

1. active participation from each company was ensured,

2. key company personnel were more likely to attend, and

3. minimal impact on company productivity was incurred.

An alternative approach, to hold a single meeting in a fixed location, was recognized as a greater hardship on companies who wished to participate, as this would require key personnel to be away from the plant for at least a full day.

The DAMA representatives who participated in this study found that visiting these companies at their locations was essential for getting a better understanding of the broader issues they face. Meeting with company officials in their own environment afforded first hand visibility into the scope of the operation and the levels of manufacturing technology and information technology in place. Many of these visits included a tour of a manufacturing facility, which revealed the company's production methods and product lines.

The visits were conducted informally, attended by the company president or vice president and usually one or more other key individuals. The focus of each visit was to identify the information technology (e.g. computers, networks, software, databases) in use, and to "brainstorm" about ways current and advanced information technology could be utilized to benefit the company in question. It was clearly communicated to each company that DAMA was not in the position to provide funds, and that DAMA could only offer solutions that have broad impact on this sector of the ITC.

Additional visits are anticipated with companies in Southern California and New York.

\section{Findings}

A number of common themes surfaced in these visits and are described below.

\subsection{Areas of Interest}

The areas of potential benefit, as identified by the companies participating in this study, are briefly described here. For the purpose of this study, areas of interest are limited to those which can be affected by information technology.

1. Low-Cost EDI. The ability to communicate American National Standards Institute (ANSI) X12 Electronic Data Interchange (EDI) transactions with other companies, primarily customers or potential customers, at significantly less cost than is readily available today from commercial software vendors and Value Added Networks 
(VANs). Many companies who expressed interest in low-cost EDI had no immediate need for it, but thought such a capability would enhance their ability to attract and do business with potential large new customers. At least one company indicated that it may be forced to use EDI by one or more of its customers. Simple EDI exchange with multiple customers is also of interest.

2. Sourcing. Using information technology tools to find information of interest to the company. For example, some companies wanted the ability to find information about fabrics that are available for sale from the manufacturer or other fabric source. Such information would include amount, color, width, components, weave, and other specifications of a given fabric. This example assumes that fabric providers collect such information and would share it in an electronic form.

3. Communication with Customers, Suppliers. Any mechanism that would improve and ease the current task of communicating with external entities. The most frequent issues here are with multiple trading partners, each of which require the same type of information but in different formats. Currently, most communication is done by fax and phone. In at least one instance, interest was expressed in making sure such communication was secure.

4. Production Planning. A tool to automate production planning and scheduling. Many companies are now faced with producing a much larger number of stock keeping units (SKUs) than ever before. Primary contributors to this increase include a larger number of available colors, sizes, and options on a given garment style, along with smaller runs than was previously the norm. This explosion of SKUs has led to significantly increased complexity in production floor planning and scheduling.

5. Automated Order Processing. A mechanism for translating incoming orders into a format that could be used for production planning and scheduling. Features include determining critical path, generating cut ticket, trim sheet, marker layout, and instruction list for operators.

6. New Product Development. A means of showing new products which reduces the need to transport actual physical samples. Possibilities range from simply sharing images of products to a full collaborative development environment. The current product development cycle is much longer than desired, and an appropriate set of tools to simplify or enhance the process should cut the time dramatically.

7. Quality Tracking. An enhanced bundle tracking system to include information about the stations a garment has passed through, the time the garment was at each particular station, the operator(s) at each station at the time the garment passed through, etc., to assist when tracking down and correcting production errors.

8. In-process Inventory Tracking. A tool to quantify and locate in-process inventory.

9. Raw Materials Inventory Tracking. An automated tool for tracking and inventorying incoming raw materials.

Table Error! Style not defined.-Error! Bookmark not defined. depicts the number of companies visited that expressed an interest in each area. 


\begin{tabular}{|c|c|}
\hline Area of Interest & Number of Interested Companies \\
\hline 1. Low-Cost EDI & $\checkmark \checkmark \checkmark \checkmark \checkmark$ \\
\hline $\begin{array}{l}\text { 2. Sourcing } \\
\text { - Current, short-term equipment and } \\
\text { capacity } \\
\text { - Small lot fabrics } \\
\text { - Availablefabrics } \\
\text { - Fabric development plans }\end{array}$ & $\begin{array}{l}\checkmark \\
\checkmark \checkmark \checkmark \checkmark \\
\checkmark \checkmark \\
\checkmark \checkmark\end{array}$ \\
\hline $\begin{array}{l}\text { 3. Communication with Customers, } \\
\text { Suppliers }\end{array}$ & $\checkmark \checkmark \checkmark \checkmark \checkmark \checkmark$ \\
\hline 4. Production Planning & $\checkmark \checkmark \checkmark \checkmark$ \\
\hline 5. Automated Order Processing & $\checkmark \checkmark \checkmark$ \\
\hline 6. New Product Development & $\begin{array}{ll}\checkmark \checkmark \\
\end{array}$ \\
\hline 7. Quality Tracking & $\checkmark$ \\
\hline 8. In-process Inventory Tracking & $\checkmark \checkmark$ \\
\hline 9. Raw Materials Inventory Tracking & $\checkmark$ \\
\hline
\end{tabular}

Table Error! Style not defined.-Error! Bookmark not defined. Areas of Interest, quantified by area

Table Error! Style not defined.-Error! Bookmark not defined. shows the areas of interest expressed by each company. 


\begin{tabular}{|c|c|c|c|c|c|c|c|c|c|}
\hline Company & Ar & s of & nter & & & & & & \\
\hline & 1 & 2 & 3 & 4 & 5 & 6 & 7 & 8 & 9 \\
\hline A\&Z Industries, Ltd & $\checkmark$ & $\checkmark$ & & & & $\checkmark$ & & & \\
\hline Ashmore Sportswear & & & $\checkmark$ & & & & & $\sqrt{ }$ & \\
\hline Craig Industries & & & $\checkmark$ & & & & & & \\
\hline Encore Textiles, Inc. & $\checkmark$ & & & $\checkmark$ & $\sqrt{ }$ & & & $\sqrt{ }$ & \\
\hline Granite Knitwear, Inc. & & & $\checkmark$ & & & & & & \\
\hline Hamrick Industries & & & & & & & & & \\
\hline Hemingway Apparel Inc. & & & $\checkmark$ & $\checkmark$ & & & & & \\
\hline Lebanon Apparel & & & $\checkmark$ & $\checkmark$ & & & & & \\
\hline Loungewear Manufacturing Corp. & $\checkmark$ & $\checkmark$ & & & & & & & $\checkmark$ \\
\hline $\begin{array}{l}\text { Lynn Manufacturing, Division of } \\
\text { Courtland }\end{array}$ & & $\sqrt{ }$ & & & & & & & \\
\hline Pattern Design Unlimited, Inc. & & $\checkmark$ & $\checkmark$ & & & $\checkmark$ & & & \\
\hline Swansea Manufacturing Co. & $\checkmark$ & & & $\checkmark$ & $\checkmark$ & & & & \\
\hline The KYM Company & & $\checkmark$ & & & $\checkmark$ & & $\checkmark$ & & \\
\hline Virginia Apparel Corporation & $\checkmark$ & $\checkmark$ & & & & & & & \\
\hline
\end{tabular}

Table Error! Style not defined.-Error! Bookmark not defined. Areas of Interest, organized by Company name

In addition to the above areas of interest, a number of companies indicated they would be interested in receiving training and attending seminars on various subjects. One company suggested that for the very small contractors that it uses, video tape based training would be most valuable.

\subsection{General Observations}

Some interesting comments surfaced during these visits, many of which were repeated at more than one company. These comments did not have direct bearing on information technology needs or solutions, but they are worthy of note in this report:

- Some companies are making the transition from pure contractor to contractor/manufacturer

- Some still refuse to hold or cannot purchase fabric or finished goods inventory

- The ability to purchase small amounts of fabrics is key to flexibility and, in many cases, customer response

- Some fabric producers are unwilling to sell small amounts

- Flexibility is key to survival

- Some companies are willing to take on "odd jobs," while others are sticking strictly to their traditional business

- NAFTA is having significant impact, removing from US companies work such as

- Stock items, such as plain white t-shirts,

- low-complexity work that has few SKUs and few steps to produce, 
- items not requiring a high level of quality

- high volume orders

Many companies are taking on fill-in work for replenishment of orders that originally went to other countries

- Cash reserves are slim to none in these classes of companies

- US, Japanese, and German customers pay more for higher-quality US-made products

- Customer demands are increasing in areas of on-time delivery and quality

- A wide range of operator wages is paid, directly influenced by local competition

- A wide-spread problem is getting on-time delivery of quality goods from suppliers

- A wide range of very different and usually custom software is used at these companies for conducting business, tracking work in progress, managing payroll, etc.

- Contracts are one-sided; buyer may pull out with no notice leaving contractor with unplanned available capacity; deadlines for finished products to not slip when customer-supplied piece goods arrive late

\section{Recommendations}

The DAMA Project considers these visits and the information they have brought to light as invaluable. It appears that there are definite needs that DAMA has the capability to address. At the same time, it is recognized that this study focused exclusively on apparel manufacturers and contractors located primarily in the U.S. Southeast, and that there are other significant pockets of similar activity located in Southern California and in New York. Given this, the first recommendation is to conduct similar visits with representative companies in these other two locations. Action will be taken on this recommendationimmediately.

The second recommendation is to take into consideration some of the areas of interest listed in Section 3.1 Areas of Interest. Of particular interest are the first three: LowCost EDI, Sourcing, and Communication with Customers, Suppliers. These three items appear to reflect the most frequently expressed needs of this study group, and we speculate that the other groups to be visited will have similar needs. In addition, DAMA has already obtained expertise, and in some cases developed tools, that will directly apply to these three areas of interest.

The third and final recommendation is to update this report with the information that will be obtained from visits to companies in Southern California and New York, and plan to address 2-3 stated areas of interest in this fiscal year (October 1997 - September 1998).

\section{Future Plans}

In the immediate future, trade associations in Southern California and New York, including Garment Contracting Association of Southern California (GCASC) and Garment Industry Development Corporation (GIDC) will be contacted to arrange visits with 
representative companies that are part of their membership. It is hoped that these visits can be arranged and executed before the end of 1997.

Once candidate areas of interest have been identified and approved for work within DAMA, companies who expressed interest in those areas will have the opportunity to work with DAMA developers to refine the scope, requirements, and goals of that work. Ideally, pilots will be implemented which engage companies who are part of this study, along with some of their trading partners, who may also be DAMA member companies. Such pilots would likely involve the introduction of new technology or mechanisms into the participating companies and operate for some extended period of time. Successfully piloted technologies would become candidates for commercialization, which would make them available to the entire industry as commercial products.

It is also hoped that the relationships formed as a result of this study, along with the introduction and utilization of new technology, will lead to stronger and more cooperative relationships among the study and pilot participants and eventually throughout the industry. Several of the participants in this study have noted that the industry, now faced with new challenges from the government and from abroad, must work cooperatively to survive. The introduction of new technology can only serve to facilitate some of the cultural and operational changes needed to enable this cooperation; it cannot cause them. However, broadcasting the success stories achieved through this work will help foster new partnerships throughout the industry.

\section{Contact Information}

Jim Lovejoy

DAMA Industry Project Director

Textile/Clothing Technology

Corporation $\left(\mathrm{TC}^{2}\right.$ )

211 Gregson Drive

Cary, NC 27511-7909

919-380-2184

jlovejo@tc2.com
Carolyn Wimple

Deputy Project Leader

Lawrence Livermore National Laboratory(LLNL)

P. O. Box 808 L-156

Livermore, CA 94551

510-423-3522

wimple@tis.llnl.gov
Leonard Brewington

Director, Quick Response

Milliken \& Company

P. O. Box 1926, M-132

Spartanburg, SC 29304

864-503-2299

leonard_brewington@milliken.com

\section{Appendix A - US Small Business Administration (SBA) Definition of Small Business}

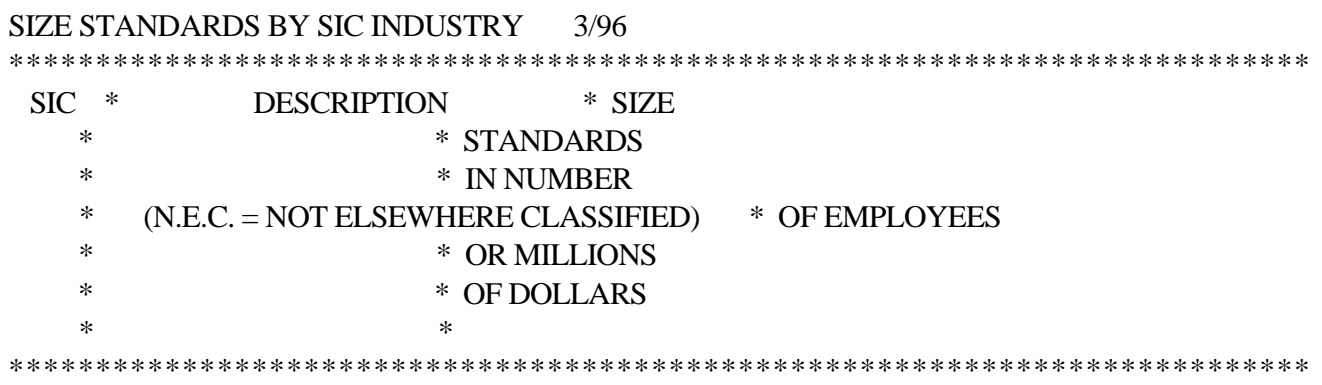


DIVISION D**MANUFACTURING2

$* * * * * * * * * * * * * * * * * * * * * * * * * * * * * * * * * * * * * * * * * * * * * * * * * * * * * * * * * * * * * * * * * * * * * * * * * * *$

MAJOR GROUP $23 * *$ APPAREL AND OTHER FINISHED PRODUCTS

MADE FROM FABRICS AND SIMILAR MATERIALS

$* * * * * * * * * * * * * * * * * * * * * * * * * * * * * * * * * * * * * * * * * * * * * * * * * * * * * * * * * * * * * * * * * * * * * * * * * * *$

$2311 \ldots *$.... Men's and Boys' Suits, Coats and Overcoats .... *.... 500

$2321 \ldots$ *... Men's and Boys' Shirts, Except Work Shirts .... *.... 500

$2322 \ldots . . . *$ Men's and Boys' Underwear and Nightwear ...... *.... 500

2323 .... * Men's and Boys' Neckwear.................. *.... 500

2325 .... * Men's and Boys' Separate Trousers and Slacks .. * ..... 500

$2326 \ldots *$ *... Men's and Boys' Work Clothing .................... 500

$2329 \ldots . . . *$ Men's and Boys' Clothing, N.E.C. ............ * ..... 500

$2331 \ldots$ *.. Women's, Misses', and Juniors' Blouses *

* and Shirts ................................ 500

$2335 \ldots$.... Women's, Misses', and Juniors' Dresses ....... * ..... 500

2337 .... * Women's, Misses', and Juniors' Suits, Skirts, *

* and Coats ................................. 500

2339 .... * Women's, Misses', and Juniors' Outerwear, N.E.C * ..... 500

$2341 \ldots$ * Women's, Misses', Children's, and Infants' *

* Underwear and Nightwear ........................ 500

$2342 \ldots . .$. Brassieres, Girdles, and Allied Garments ..... * .... 500

$2353 \ldots *$ *... Hats, Caps, and Millinery ...................... 500

2361 .... * Girls', Children's, and Infants' Dresses, *

* Blouses, and Shirts ......................... 500

$2369 \ldots . . *$ Girls', Children's, and Infants' Outerwear,

* N.E.C. ..................................... 500

$2371 \ldots . *$ Fur Goods ................................. 500

$2381 \ldots *$ *... Dress and Work Gloves, Except Knit and *

* All-Leather ................................ 500

$2384 \ldots . . *$ Robes and Dressing Gowns ...................... 500

$2385 \ldots . . . *$ Waterproof Outerwear ......................... 500

$2386 \ldots *$.... Leather and Sheep-Lined Clothing ................. 500

$2387 \ldots . . *$ Apparel Belts ............................ 500

$2389 \ldots *$ *... Apparel and Accessories, N.E.C. .................. 500

$2391 \ldots *$ *... Curtains and Draperies ....................... 500

$2392 \ldots$ *... Housefurnishings, Except Curtains and Draperies * ..... 500

$2393 \ldots . . *$ Textile Bags .............................. 500

2394 .... * Canvas and Related Products .................... 500

2395 .... * Pleating, Decorative and Novelty Stitching, *

* and Tucking for the Trade .................... 500

2396 .... * Automotive Trimmings, Apparel Findings, and *

* Related Products ............................ 500

2397 .... * Schiffli Machine Embroideries ................... 500

$2399 \ldots . . . *$ Fabricated Textile Products, N.E.C. .......... *... 500

$* * * * * * * * * * * * * * * * * * * * * * * * * * * * * * * * * * * * * * * * * * * * * * * * * * * * * * * * * * * * * * * * * * * * * * * * * * *$ 
Demand Activated Manufacturing Architecture

SME Report

Connectivity and Infrastructure

Version 1.0 


\title{
Appendix B - Organization for Economic Cooperation and Development (OECD) Definition of SME
}

\author{
Small and Medium-sized Enterprises
}

\section{What is a Small and Medium-sized Enterprise (SME)?}

The term SME covers a wide variety of definitions and measures and there is no official or universally accepted definition of an SME.

The definitions and their basis vary widely among countries, but the most common definitional basis in OECD countries is employment -- in general an SME has less than 500 employees, although many countries use a lower cut-off, say 300 or 100 employees. Some countries differentiate between manufacturing and services SMEs -- with a services SME usually defined to be smaller than a manufacturing one.

Some countries distinguish between autonomous SMEs and those SMEs that are connected to a larger enterprise or group, or identify an SME in terms of management structure (personal involvement of the owner or family-owned, for example).

Finally, statistical definitions of SMEs often differ from those used for policy implementation purposes; for example although a firm with 600 employees may not be regarded as an SME for statistical purposes, it may still be able to gain access to public support programmes designed for SMEs.

The main feature of an SME is that it is "not large", in the sense that an SME is not in the core of the largest 10 or 20 per cent of firms in that market or industry. This leads to a rough convention for categorising SMEs:

- micro: 1 - 4 employees;

- very small: 5 - 19 employees;

- small: 20 - 99 employees; and

- medium: 100 - 500 employees.

Last update 28 March 1997

http://www.oecd.org/dsti/sme/21def.html

9 
Demand Activated Manufacturing Architecture

SME Report

Connectivity and Infrastructure

Version 1.0 


\section{Appendix C - Visit Reports}

SME Visit Report
Date:
July 23, 1997
Time:
9:00am
Location: Allentown, PA
Attendees: Tony ElChaar, President \& CEO A\&Z Industries, LTD
Leonard Brewington, Milliken \& Company
Ernest Vosti, LLNL
Carolyn Wimple, LLNL

Company Background:

Company Name:

A\&Z Industries, LTD

Primary Business:

Manufacturer

Size:

300 employees, 125 at Allentown facility

Contractor Organization:

AAMA

Company Type:

Manufacturer of fashion products

Product Line:

Fashion clothing, dresses, jackets

Customer Types:

Private Label Retailers

Computer/Network Usage

E-mail:elchaar@aol.com

Web Site:

Computers: $\quad$ PCs on Windows 95, Gerber software

EDI: $\quad$ They have two customers on two different VANs that require EDI. It costs Tony $\$ 1000 /$ mo per VAN.

Needs

1. The product development cycle is currently $6+$ weeks. Tony would like to see if DAMA technology could be applied to reduce the product development time. He envisions a system that would allow the designer, the manufacturer, and the fabric maker to collaborate electronically to share design information, fabric specifications, prices, etc. The potential is to reduce the product development time to approximately three weeks, cutting $3+$ weeks of time. Potential companies that would participate in a pilot are small to medium sized private label retailers. Any pilot that would be developed would have to start small so that it would not require a lot of investment by the retailer to participate and would have a higher probability of success.

2. He sees a need to interact with fabric vendors on-line. He would like to see the Apparel Exchange concept extended to include more detail about the products that are available. 


\section{Miscellaneous Notes}

1. Some companies have gone to Mexico to produce fashion products. There are quality problems with these products, although quality is improving.

2. We discussed at some length the cultural issue in the textile industry whereby companies are very reluctant to share information even though it is commonly known or can easily be derived from other data. This is a major hurdle that would have to be crossed in any collaborative pilot within this industry.

3. Tony sees EDI as costly and of no advantage to him.

4. A\&Z performed an internal study that showed that the actual work processes to develop a product only amount to about 3 weeks. The rest of the $6+$ weeks is wasted time waited for FedEx's, phone calls, fax's, travel to meetings, etc. 
SME Visit Report

Date: $\quad$ July 22, 1997

Time: $\quad$ 9:00am

Location: Akron, PA

Attendees: Dennis Ashcroft, Ashmore Sportswear

Selina Ashcroft, Ashmore Sportswear

Leonard Brewington, Milliken \& Company

Ernest Vosti, LLNL

Carolyn Wimple, LLNL

Company Background:

Company Name:

Ashmore Sportswear

Primary Business:

T-shirt Manufacturer

Size:

2300 employees

Contractor Organization:

AAPN (AACA)

Company Type:

Primarily private label manufacturer. Knits common sizes

$(60 \%)$ in-house, $40 \%$ contracted out. Originally only a

knitting plant

Product Line:

T-shirts and other similar knit tops

Customer Types:

Two primary customers, several large sports apparel companies, and 18 very small companies

Computer/Network Usage

E-mail:7585625@mcimail.com

Web Site: www.ashmore-sportswear.com

Computers: Have PCs, not networked, use fax and e-mail, heavy Lotus use. Planning to modernize systems and install network, improve usage

EDI: $\quad$ See no current need for EDI since they don't deal with retailers

Needs

1. Looking for software to "de-skill" positions; make accurate decisions for an operator. Software must be user-friendly, not requiring expert computer background

2. Looking for seminars focused on planners, schedulers, not just targeted at executives

Miscellaneous Notes

1. Originally a knitting plant, then added cut and sew in 1981

2. All work in process is made to order; rarely make to stock; when do make to stock, it is targeted at largest customers

3. 45 days from yarn in thru knit, dye, manufacture and ship

4. All manufacturing is done domestically

5. 3 production facilities -2 in PA, 1 in VA

6. Does not sell directly to retailers - only private label 
7. Customer demands are greater now than they used to be, e.g. last year 2 weeks late was ok, now 1 day is a big deal.

8. Customers are now requiring nearly $100 \%$ on time correct shipment. A year ago $90 \%$ was acceptable

9. Quality issues and delays have major impact

10. One major problem is with the quality of incoming yarn. Poor yarn in causes problems down the line.

11. Would prefer better information flow from suppliers. Poor information flow is probably due to suppliers' smaller margins and decreased staff

12. Ashmore is probably also providing poor and/or un-timely information to its customers

13. Timely deliveries is a problem

14. Previously just produced blank shirts; as of 6 months ago is now coordinating printing of shirts and packaging for customers

15. Now entering in the business of sourcing customers who ask for work Ashmore doesn't do to other AAPN members 
SME Visit Report

Date: $\quad$ August 28, 1997

Time: 2:00pm

Location: Lamar, SC

Attendees: Larry Crolley, Craig Industries

Ronnie Nixon, Craig Industries

Debra Reynolds, Craig Industries

Steve Freudenthal, Milliken \& Company

Bill Grimmell, ORNL

Carolyn Wimple, LLNL

Company Background:

Company Name:

Primary Business:

Size:

Contractor Organization:

Company Type:

Product Line:

Customer Types:
Craig Industries

Golf shirts and t-shirts

300 employees in 3 plants

SEAMS

Contracting only

Golf shirts and t-shirts

6-8 primary customers: through Sunrise Apparel, products are sold to Sears, JCPenney, Dillards, Casual Mill, Kmart; through Willow Point, sell printables to private label customers, Impressions, and South Carolina T's

\section{Computer/Network Usage}

E-mail:none

Web Site: none

Computers: have a few non-networked 486s which have access to a main server running Theos. This server runs a customized system written specifically for Craig.

EDI: $\quad$ Was requested once by Liz Clairborne, but no longer needed

Needs

1. Interested in sharing information electronically with customers. See information sharing and cooperation as a way to help the industry.

2. Would like to cut fabric for 807 companies and could use assistance in finding customers.

Miscellaneous Notes

1. Looking for big growth in Germany and Japan. These countries have higher base wages. 
2. Expect $20 \%$ of product to be sold to Japan in $97-98$. Japan highly values "made in USA." They use Craig's products in Catholic school uniforms, corporate work, and purchase through Brooks Bros.

3. Have a lot of higher technology in new sewing machines

4. Craig is proactive about interacting with and helping their customers

5. It is easier to service a $\$ 7-20 \mathrm{M}$ company than a $\$ 100 \mathrm{M}$ company

6. Use computer-generated (not bar-code) bundle tickets. Numbers are entered by hand then transmitted to their Payroll system.

7. Computer programming support is contracted out

8. Inventory, work in progress, cut work, shipped orders are recorded on computers

9. Information can be downloaded from main server to PCs

10. Customers provide a cutting ticket which allows Craig to cut fabric when fabric arrives. This is all planned in advance with the customer.

11. Have no need to source fabrics

12. Craig likes to do projects other companies don't like to do.

13. Craig enjoys the challenge of doing odd lots; does not see the added planning complexity as a problem

14. Would benefit from availability of shorter runs from mills.

15 . Operators are paid a base wage plus piece work, average $\$ 7.00 / \mathrm{hr}$ 
SME Visit Report

Date: $\quad$ June 25, 1997

Time: $\quad$ 9:00am

Location: Monroe, NC

Attendees: Dan Bulluck, Encore Textiles

Nancy Bulluck, Encore Textiles

Skip Forbes, Milliken \& Company

Ernest Vosti, LLNL

Carolyn Wimple, LLNL

Company Background:

Company Name:

Primary Business:

Size:

Contractor Organization:

Company Type:

Product Line:

Customer Types:
Encore Textiles

T-shirt Contractor, includes some private-label

manufacturing

$\sim 125$ employees, $\sim \$ 6$ million

AAPN (AACA)

$50 \%$ Contractor, $50 \%$ private-label manufacturing

T-shirts, and other similar knit tops (no placket)

Primarily higher-end name brands, including Cal Cru

(Granite Knitwear), Levi, Hanes, Adiddas, Calvin Klein, Jerzees (Russell)

Computer/Network Usage

E-mail:debulluck@aol.com; personal only, none used by company

Web Site: Utilizes AAPN pages

Computers: Utilizes some PCs for business applications, MS Office

EDI: None, sees this as a handicap, but is reluctant to employ multiple different EDI systems to satisfy different new customers

Needs

1. Need help working with large retailers. They're not big enough to do EDI and respond to their demands

2. Would like a system to track in-process inventory

3. Would like a system to explode incoming orders; determine critical path

4. Would like a system that does capacity analysis

5. Need to compete with big manufacturers to service big retailers

6. Would be interested in doing EDI flexibly so they can do EDI with anyone, even if as part of a consortium with other companies.

7. Need assistance with inventory control for seconds

8. Need expertise, not money 
9. Sees a niche for sharing special types of data such a photo scans, spec sheets, etc.

10. Could use a system to help automate bundle tracking and/or completion and payroll. Currently, the piece ticket on a bundle is hand-written and glued to a sheet when an operator completes her task on a bundle. The sheet of tickets is later analyzed to count the number of pieces completed and calculate payroll. A bar code on the ticket rather than hand written notes might help.

11. Computer-based tool to help with production planning would be helpful

Miscellaneous Notes

1. Process 5000-6000 dozen/week

2. Keeps no inventory. All work in process is already sold

3. Contracts and purchases yarn that is knit into fabric

4. $50 \%$ of private label work goes to catalog business

5. Cut and Sew industry doesn't really know what its capabilities are with respect to production planning. A computer-based tool would help with this.

6. Cut and Sew is a very labor-intensive industry, as opposed to textile production which is capital intensive. It has very little automation, very little capital.

7. Constantly fighting their customers' trend to hire offshore contractors to survive. Used to make $10 \mathrm{~K}$ dozen white or ash plain T-shirts for Sara Lee, but all this simple business went off shore.

8. Now does $\sim 15$ styles/week $+\sim 38$ colors. Greatly increases complexity of production planning

9. Average lot size is 100 doz. and 5 sizes; 20 doz. of an SKU

10. $20 \%$ of business is in "+" sizes - XXXXL, as fill ins from off-shore production

11. US manufacturers are primarily doing high-end work -- high cost

12. Private label makes this company more vulnerable. Much capital and inventory is tied up, and it takes 30-60 days to get paid for their product.

13. A major dilemma is what percentage of his business should be private label vs. volume production to maximize profit.

14. Workforce is paid hourly and by throughput, ave payroll is $\$ 8.68 / \mathrm{hr}$.

15. Provides good benefits to workers - health, dental, education.

16. Company strengths: short lead time and small lot sizes.

17. Gets a few hits/calls per day from AAPN web site. AAPN has a close-outs section in its web.

18. There is a service available that would track production for a fee 
SME Visit Report

Date: $\quad$ June 25, 1997

Time: $\quad 1: 00 \mathrm{pm}$

Location: Granite Quarry, NC

Attendees: Mike Jones, Granite Knitwear

Skip Forbes, Milliken \& Company

Ernest Vosti, LLNL

Carolyn Wimple, LLNL

Company Background:

Company Name:

Primary Business:

Size:

Contractor Organization:

Company Type:

Product Line:

Customer Types:
Granite Knitwear

T-shirt Manufacturer

$\sim 150$ employees, $\sim \$ 6$ million

AAPN (AACA)

Primarily Manufacturer (Cal Cru label) and other "private labels" for artists and screen printers T-shirts, and other similar knit tops (some with placket) Primarily screen printers and T-shirt artists, embroiderer who prints/appliques on plain fabric

Computer/Network Usage

E-mail: calcru@mail.interpath.net; corporate account, received one e-mail product order in Nov. 1996

Web Site: Does not utilize AAPN pages; plans to have web site in fall 1997

Computers: Has "mainframe" (Kato Kontil (?)) for AP, AR, Payroll (Byte SW, Greenville, SC), Billing Corporate network of PCs doing internal e-mail, word processing, spreadsheets

EDI: $\quad$ None

Needs

1. Needs better ways to forecast its sales

2. Would like to reduce its 8-week lead-time

3. Would like to get order status from suppliers

Miscellaneous Notes

1. Sales via catalog and sales reps on the road

2. Increase of exported work lowers price of goods to prices lower than Granite can meet

3. Has much unsold inventory; replenishes this inventory from orders

4. Thruput is 5000 doz. per week

5. Produces 200-500 SKUs 
6. Inventory control and production planning systems use data entered by hand from received goods and filled orders 
SME Visit Report

Date: $\quad$ August 27, 1997

Time: $\quad$ 9:00am

Location: Gaffney, SC

Attendees: Michael Hamrick, Hamrick Industries

Steve Freudenthal, Milliken \& Company

Bill Grimmell, ORNL

Carolyn Wimple, LLNL

Company Background:

Company Name:

Hamrick Industries

Primary Business:

Clothing retail, and women's clothing manufacturing

Size:

2500 employees (216 sewing operators)

Contractor Organization: $\quad$ SEAMS

Company Type:

Primarily retail. Manufacturing primarily for Hamrick's retail stores, some private label contracting. Also has a dying/finishing plant, a knitting plant.

Product Line: Women's/Misses knit and woven fashion clothing

Customer Types: Approximately 2000 smaller wholesale companies

Computer/Network Usage

E-mail:none

Web Site: none

Computers: Have several networked and remote PCs and AS400, 7 AS400 programmers, 2 PC network programmers. Use internally-developed software. Remote PCs in plants access AS400 data via dial-up connection to upload payroll information. Buyers also have PCs. Some buyers may share files - not sure.

EDI: $\quad$ See no current need for EDI, no demand for it from customers

$\underline{\text { Needs }}$

1. Looking for more software

2. Looking for help with evaluating and migrating to new software

3. May be interested in software to assist with production management

Miscellaneous Notes

1. Its employees manufacture $\sim 25 \%$ of its own retail product

2. $35-40 \%$ of its total production is done internally, the rest is contracted out to places in NY

3. Produce many styles, including knit tops

4. Styles are constantly changing - it holds no stock items

5. Most production occurs in advance of the season, and it does some replenishment 
6. Use primarily domestic fabric, although it does use some micro denier from Japan

7. It has 16 sales people to support its customer base

8. It contracts with some plants in Mexico, one of which does work for JCPenney

9. It has been using bar-codes (not UPC) in its plants since 1986-87 to control inventory and assist with retail re-order

10. It is currently upgrading its retail software systems

11. Hamrick's has 25 stores in the Carolinas and Tennessee, six manufacturing plants, one knitting, one dye/finish plant

12. Patterns are created by hand, markers are computerized, cutting done manually

13. Production manager must currently look at reports to formulate production decisions

14. For sourcing fabric, buyers visit known vendors in NY and other areas

15. Not interested in getting small amounts of fabrics from jobbers or textile mill overruns. Need to order goods in large amounts. Color matching is very important.

16. Drawbacks of electronic fabric sourcing - inaccuracy of color, unable to touch fabric (hand)

17. Sales force uses books produced via CAD for showing/selling prototypes to customers

18. Prefer not to hold finished inventory for customers; will sometimes hold fabric

19. Subcontractor leads are obtained by word-of-mouth, based on reputation of contractor and a good recommendation from a trusted party

20. It is not pursuing larger companies for customers; would like to pursue mid-sized chains

21. It is difficult to stay in manufacturing because it is difficult to find skilled people at its pay level, easy to find other jobs that pay better 
SME Visit Report

Date: $\quad$ August 28, 1997

Time: $\quad$ 9:00am

Location: Hemingway, SC

Attendees: Jack Marsh (and others), Hemingway Apparel

Steve Freudenthal, Milliken \& Company

Bill Grimmell, ORNL

Carolyn Wimple, LLNL

Company Background:

Company Name:

Hemingway Apparel

Primary Business:

Women's and children's underwear and intimate apparel

Size: 280 employees in 1 plant (down from 3303 years ago)

Contractor Organization: SEAMS

Company Type:

Contracting only

Product Line:

high-quality regular and flat-seam knit, woven, tricot, velour

Customer Types: sleepwear, some lingerie Manufacturers that market to JCPenney, Dillards, Victoria's Secret, Gap, Banana Republic, Belk's, Wal-Mart

Computer/Network Usage

E-mail:2 accounts via uunet (addresses?)

WebSite: in progress

Computers: Have 8 PCs, most are in the front office; one is used for time and attendance and is tied into the payroll PC. Payroll PC can access subset of information on Accountant's PC. Another PC is used to record bundle tickets, and is connected to a computer in the engineer's office.

Administrative systems are stand-alone, use primarily office productivity tools. Also have a 386 running SCO UNIX which is used for order entry, manufacturing and inventory tracking

EDI: $\quad$ Not currently done; direct customers do not require. Might need EDI if partnership were formed with a retailer.

$\underline{\text { Needs }}$

$\overline{1 .}$ Need inexpensive, flexible, user-configurable method to better communicate info in various formats to various customers

2. Interested in flexible production planning tool that would interface with their existing system

Miscellaneous Notes

1. Capacity is typically over-booked $20 \%$. This work is sub-contracted out 
2. Plant has been in operation since 1963, under current ownership since 1978. A second plant was opened in 1989 and subsequently closed in 1995

3. Current focus is on becoming more agile - taking on new product lines (e.g. Men's Activeware) and working with customers to develop prototype products that may ultimately be taken offshore for production

4. No current plans for products with Hemingway label - prefer to stay with known contract-type business

5. Optimistic about eventual return of much contracting work to domestic soil

6. Tend to use larger sub-contractors, not 'mom \& pops' or 'sweat shops.'

7. Customers sometimes deliver materials late but still expect on-time delivery of final product. This makes scheduling difficult.

8. Difficult to deliver information to customers - nearly all customers want the same information but in different formats, e.g. general reports, invoices.

9. Hemingway doesn't advertise. In the process of developing a web page.

10. Current customers selected Hemingway based on the company's long-standing reputation.

11. Employees are paid on piece rate. At $80 \%$ of maximum, operator gets minimum wage.

12. Average wage $=\$ 7.50 /$ hour on stable products (e.g. panties, t-shirts), $\$ 5.50$ or more on dynamic product lines (e.g. ladies' sleepwear)

13. Not much outside competition for employees any more (previously were losing people to Tupperware)

14. Use computerized inventory tracking system for fabric inventory

15. Larger customers are most concerned about format of provided information. Data at Hemingway is stored in a spreadsheet and manually manipulated to generate shortage reports, packing slips, invoices, etc. All reports are delivered to customers via fax.

16. Each customer's inventory is stored separately to satisfy customer reporting needs. These are $\sim 30$ relational flat files (no keywords).

17. Have one computer service person on the payroll. He has developed much custom software for Hemingway. The closest commercial approximation of this custom software is called Satellite Plus, which is AS400-based with a PC interface. It costs $\sim \$ 300 \mathrm{k}$ - too expensive. 
SME Visit Report

Date: $\quad$ July 24, 1997

Time: $\quad$ 8:30am

Location: Lebanon, VA

Attendees: Jeoff Bodenhorst, President, Lebanon Apparel

Dan Vipperman, VP Operations for Lebanon Plant

Marc Camnitz, Executive VP

Leonard Brewington, Milliken \& Company

Ernest Vosti, LLNL

Carolyn Wimple, LLNL

Company Background:

Company Name:

Lebanon Apparel

Primary Business:

Contractor

Size:

650 employees

Contractor Organization:

AAPN (AACA)

Company Type:

Contractor of uniforms for healthcare and fast-food

industries, sportswear

Product Line: Uniforms, smocks, shirts, pants, outerwear

Customer Types:

Crest, McDonalds

Computer/Network Usage

E-mail:jeoffbb@compunet.net

WebSite: http://www.usawear.org/lebanon/

Computers: PCs on Windows 95

EDI: No capability now. They use fax for their "Quick response" orders.

Needs

1. It would like to see a customer-driven work (production) planning system. To meet this need, it is currently thinking about having its large customer, Crest, have one of its employees at Lebanon's facility to help optimize the production process to meet Crest's needs in the most efficient way. If this function were computerized, it would require the customer to lay out the delivery schedule in more detail than it currently does; in other words, more granularity in its customer orders. This would involve closer collaboration with its customers' planners. Jeoff envisions a GUI that looks like an air traffic control screen that would give a quick vision check on how orders are progressing through its plant(s).

2. Better communication in the industry.

3. Jeoff also envisions "multifunctional manufacturing" where a module could perform all the functions to produce that product: cut, sew, and finish.

$\underline{\text { Miscellaneous Notes }}$ 
1. Lebanon Apparel has worked very hard to reduce the production time in its plant. It boasts 3-4 day turn-around for simple products. This has become one of its competitive advantages.

2. It is currently $40 \%$ modular, $60 \%$ traditional production line.

3. Lebanon is interested in moving to be a manufacturer. 
SME Visit Report

Date: $\quad$ July 22, 1997

Time: $\quad$ 1:00pm

Location: Ephrata, PA

Attendees: David Miller, President Loungewear Manufacturing Corp.

Larry Miller, Loungewear Manufacturing Corp.

Leonard Brewington, Milliken \& Company

Ernest Vosti, LLNL

Carolyn Wimple, LLNL

Company Background:

Company Name:

Loungewear Manufacturing Corp.

Primary Business:

Women's and children's sleepwear and robes

Size:

$\sim 140$ employees, 1 plant

Contractor Organization:

AAPN (AACA)

Company Type:

Product Line:

Primarily contracting, trying to expand into manufacturing

Wide variety of Women's and Children's Sleepwear and robes, expanding into Computer Bags.

Customer Types: $\quad$ 12 Name Brand manufacturers

Computer/Network Usage

E-mail:

Web Site: none

Computers: Have networked PCs, utilized primarily for payroll, accounting. Unit production system downloads production into payroll; traditional production tracked via bar codes

EDI: $\quad$ Has done EDI with a Kmart supplier.

Needs

1. Would benefit from a generic EDI package that would help it do EDI with a variety of retailers.

2. Need raw materials (fabric in) inventory on computer

3. Could benefit from a useful sourcing database for trim and fabric. Takes too much time on the phone to track down good sources; too hard to get small amounts and promotional stuff. Difficult to find what he needs when he needs it

4. A common web site or service for multiple jobbers and fabric manufacturers to post current fabric availability so fabric buyers have one place to go to find small amounts of new fabric would be great. Doesn't have such a problem with notions (buttons, zippers, etc.). This would help LMC do more manufacturing in small lots (100 doz.). This could also help companies like Milliken to unload overrun fabric at prices better than they currently get from jobbers. 


\section{Miscellaneous Notes}

1. Uses unit production system and traditional bundle system

2. Capacity: 2000 doz./week

3. Some customers are EDI capable and LMC would become more valuable to them if it could do EDI. Current EDI solutions are too expensive.

4. Receives orders via fax on Mondays, can turn order in about a week if cloth is in house or in delivery.

5. Manufacturer sources fabric; when LMC is the manufacturer, it sources fabric

6. Administration of $10+$ styles/week is very complex

7. Business is going offshore, forcing LMC to smaller runs. Last year lost 5000 doz. $\$$ \$300K of work to Asia

8. Is not cost effective to manufacturer to go overseas for small-medium lot orders of items that cost less than $\$ 20 / \mathrm{doz}$. - overhead cost to track progress, delivery, quality offsets potential savings.

9. Has capability to computer-generate work in process reports off unit production system 
SME Visit Report

Date: $\quad 8 / 26 / 97$

Time: $\quad 8: 45$

Location: Lynchburg, Va.

Attendees: LeonardBrewington

David Caldwell

Bruce Campbell

BillGrimmell

Perry ?

Company Background:

Company Name:

Lynn Division of Courtland Manufacturing

Primary Business:

Women's and Children's Wear

Size:

About 400 employees (total Courtland Manufacturing)

Organization:

SEAMS and AAPN (AACA)

Company Type:

Manufacturer and Contractor (also use subcontractors)

Product Line:

Dresses, Slacks, Cheerleader Outfits etc.

Customer Types: $\quad$ Lynn Bryant, Penneys, Limited etc.

Computer/Network Usage:

E-mail: $\quad$ Have email (apparently at Courtland headquarters in Appomatox Va.)

Web Site: Apparently none.

Computers: AS400 at headquarters. Of the order of 50 PCs throughout Courtland. Six at Lynchburg site are networked and have access to headquarters AS400. Have computerized marker layout system.

EDI: $\quad$ Apparently do some EDI with Penneys

Needs:

1. More rapid means to estimate material costs for rapid response to requests for quotation.

2. Would benefit from improved ease of use (in some areas) of shop floor control system (note this system was put together by two programmers who are no longer available to the firm and apparently runs on the AS400).

3. Would benefit by being able to rapidly determine externally available equipment and capacity.

4. Would benefit by knowing about fabric developments at mills (Leonard noted that Milliken tries to keep retailers aware of fabric developments).

Miscellaneous Notes:

1. Use a subcontractor in El Salvador and are starting a Mexican venture. 
2. Has gotten business through email inquiries but not significant business through this means - Has one line, where original contact was an email inquiry, that is about break even now but is hoped will grow

3. Has two computer type people who maintain AS400 systems and will help with problems that occur in P.C. usage.

4. Many subcontractors that Courtland uses are very small (most probably have a computer but are not hooked up to the Internet). Unlikely such subcontractors belong to a trade association. Suggestion was made that providing such organizations with instructional videos would be feasible way of communicating how technology could be useful to them (they wouldn't go to other sites for instruction). Trust and reputation are essential elements of relationships with such subcontractors.

5. With regard to need 1 , indicated that web fabric availability could be very useful if information could be kept up to date and fabric descriptions were sufficiently meaningful. Wondered if mills would provide full information on fabric that was available.

6. With regard to need 3, thought that maybe availability should be by code rather than name of company. 
SME Visit Report

Date: $\quad$ July 22, 1997

Time: 11:00am

Location: Reinholds, PA

Attendees: Gale Zorian, Vice President Pattern Design Unlimited

Leonard Brewington, Milliken \& Company

Ernest Vosti, LLNL

Carolyn Wimple, LLNL

Company Background:

Company Name:

Pattern Design Unlimited

Primary Business:

Design development services

Size:

$<10$ employees

Contractor Organization:

AAPN (AACA)

Company Type:

"Front end" work: designs, patterns, markers, samples are products

Product Line: Men's, women's and children's fashion clothing, hats, doll clothing

Customer Types: Customers include Disney (got this business through web), Binner, Esprit, Liz Claiborne, Jones of NY, Susan Dunn, Ge Williker, Gap, Transamerica, Nordic Gear

Computer/Network Usage

E-mail:patternd@ptdprolog.net

WebSite: www.apparelex.com/patternd and www.usawear.org/design

Computers: Have PCs on Windows 95, use sophisticated Gerber software for pattern making, grading, and markermaking.

EDI: $\quad$ Not needed for its business.

Needs

1. Would like to see more detail in ITC web sites. Today, it is mostly generic information about the company and products. What it wants is more detail about products: detailed specifications, availability, lead times, styles, etc.

Miscellaneous Notes

1. Has received lots of contacts through its web site (including Disney). Most of these contacts have been start-up companies looking for a package they can take overseas for manufacturing (knock-offs).

2. Disney is outsourcing much of its product development; it's too expensive to maintain development facilities and sample rooms. 
Demand Activated Manufacturing Architecture

SME Report

Connectivity and Infrastructure

Version 1.0 
SME Visit Report

Date: $\quad$ August 27, 1997

Time: $\quad 2: 30 \mathrm{pm}$

Location: Swansea, SC

Attendees: Harvey Hellman, Swansea Manufacturing Company, Inc.

Steve Freudenthal, Milliken \& Company

Bill Grimmell, ORNL

Carolyn Wimple, LLNL

Company Background:

Company Name:

Primary Business:

Size:

Contractor Organization:

Company Type:

Product Line:

Customer Types:
Swansea Manufacturing Company, Inc.

Sportswear, knits and wovens $\sim 100$ employees in 2 plants (down from 250)

SEAMS

Primarily contracting; currently moving into manufacturing Sports apparel, Real Tuf (Swansea private label) soccer and volleyball uniforms (new this year)

e.g. L.L. Bean, Umbro, Lands' End

Computer/Network Usage

E-mail:swanseamfg@pbtcomm.net

Web Site: www.realtuf.com

Computers: Have some PCs, most are networked.

EDI: $\quad$ Not currently using EDI

$\underline{\text { Needs }}$

1. Need help with production planning/forecasting for odd combination orders and small lot orders of soccer line - broad \# of SKUs, many colors, men's and women's and children's sizes. Question - How much data needs to be collected to do forecasting?

2. Interested in automated order processing that would generate

- Cutting ticket

- Trim sheet - items needed to make garment (bill of materials)

- Marker layout (currently looking at Scanvec $[\sim \$ 15 \mathrm{~K}]$, others are too expensive)

3. Interested in low-cost EDI with large customers

Miscellaneous Notes

1. Soccer line is difficult to manage with 2-4 week turnaround and very small orders (e.g. 11)

2. Must pay a premium for piece goods to construct orders for soccer line because orders are too small for mills' minimums

3. Soccer product line has no history

4. Doesn't want to carry inventory 
5. Difficult for small manufacturer to have suppliers deliver orders on time. Its orders are often delayed in favor of larger customer orders. Greatest difficulty is getting custom order collars.

6. Is doing some custom-made uniforms for customers who want to mix Swansea's predefined styles

7. Can't tell whether web site has generated any orders. Order processing is disconnected from the order's origin. Most come in via fax.

8. Business is seasonal, difficult to rehire laborers after Summer layoffs

9. Employees can work up to $54 \mathrm{hrs} /$ week

10. Hard to keep employees - McDonalds pays more

11. Operators are paid by piece work, average $\$ 6.30 / \mathrm{hr}$

12. Tried using modules, and while employees liked working in teams, they were reluctant to frequently change product lines. Harvey would like to try modules again because it produced high-quality products and team spirit. 
SME Visit Report

Date: $\quad 6 / 24 / 97$

Time: $\quad$ 12:00

Location: Jackson, GA

Attendees: Mark Kapiloff, The KYM Company

Richard Kapiloff, The KYM Company

Ernie Vosti, LLNL

Carolyn Wimple, LLNL

Sue Strickland, AAPN (AACA)

Company Background:

Company Name:

The KYM Company

Primary Business:

Uniform pant contractor

Size:

70 operators

Contractor Organization:

AAPN (AACA)

Company Type:

Cut and sew contractor

Product Line:

Pants for uniforms and special applications

Customer Types: Disney Corporation, Yves St. Laurent

Computer/Network Usage

E-mail:rekapp@aol.com

WebSite: http://www.usawear.org/kym.htm

Computers: Uses a computer for accounting and basic business applications. Uses

CAD system for making some complex markers (Richard primarily uses this system)

EDI: $\quad$ None

$\underline{\text { Needs }}$

1. Could really use a low-cost software application that would allow him to track the production process. They currently use "the list" which is a hand-typed, very detailed report that itemizes exactly how each order should be produced. The list is created weekly primarily by Mark. A software package would be very useful to reduce errors and speed the process of creating the list of instructions for the operators.

2. Would like a system something like what $[\mathrm{TC}]^{2}$ has that will create a marker along with instructions for producing the garment. The perceived system would accumulate orders and models and produce instructions that would optimize spreading, cutting, sewing.

3. Needs access to small lots of cloth. The big mills (e.g., Milliken) will only sell in very large lots. There used to be lots of "jobbers" who would buy from the big mills and sell in smaller quantities to the contractors. There are only a few jobbers left. Fisher Textiles is a mill that will do small runs. 
4. E-mail would help him. He has a WWW presence through AAPN, but has had no business yet.

Miscellaneous Notes

1. KYM produces approximately 4,000 pairs/week and 70,000 dozen per year

2. Its business has gotten more complex over the years: 20 years ago, it produced 4 times the volume they do today, but only had $1 / 10^{\text {th }}$ the number of customers

3. Its largest customer is the Disney Corporation

4. Most of its business is "fill-in" for work that is done off- shore. Example: Yves St. Laurent contracts most of its work off-shore and uses KYM (and presumably other contractors) when there is an error in the quantity or style/color mix.

5. Employees are primarily female, minority, and without high school education. Many of the employees are single parents

6. Uses $[\mathrm{TC}]^{2}$ training system to train its one engineer (who is also the VP of the company). It also has its operators take the training (without the tests) so they can become more familiar with the machines they use. Mark stated that this training system is the most valuable equipment investment he has ever made.

7. A year ago, KYM announced it was going out of business. Disney and several of its key customers basically said "what would it take to keep you in business?" When he named his price, they said "OK." He is apparently one of the most expensive contractors, but has loyal customers because of KYM's high level of service.

8. Mark will only do business with companies that will allow him to meet the person who signs the check.

9. Disney does everything JIT. 
SME Visit Report

Date: $\quad$ July 24, 1997

Time: $\quad 2: 30 \mathrm{pm}$

Location: Rocky Mount, VA

Attendees: Tom Mason, President Virginia Apparel Corp.

Gene Willis, VP Finance Virginia Apparel Corp.

Ernest Vosti, LLNL

Carolyn Wimple, LLNL

Company Background:

Company Name:

Virginia Apparel Corp.

Primary Business:

Woven men's and women's bottoms

Size:

$\sim 250$ employees, 1 plant, 4 retail stores

Contractor Organization:

AAPN (AACA)

Company Type:

Primarily contracting, has own label (Back Creek)

Product Line:

Men and Women's woven bottoms (slacks, shorts, skirts), rarely unconstructed tops.

Customer Types: $\quad$ Catalog sales, name brands, including Lands' End, L.L. Bean, Calvin Klein, and Nike

Computer/Network Usage

E-mail:vacorp@cablenet-va.com

Web Site: usawear.org/virginia

Computers: Have Novell-networked PCs on Windows 3.1; utilize Byte Systems Manufacturing Software

EDI: $\quad$ Is EDI capable, currently exchanging 830, 852, $832 \mathrm{w} /$ Lands' End

Needs

1. Wants to get his hands on ARMS ASAP to show to L.L. Bean Buyers at meeting in August.

2. Would benefit from less costly EDI solution. Will be expanding EDI transmissions to Lands' End and would benefit from reduced transmission costs. (L.L. Bean pays for EDI traffic both directions).

3. Would benefit from assistance in sourcing fabric, especially in production of Back Creek products

Miscellaneous Notes

1. Tom was on original DAMA committee at $[\mathrm{TC}]^{2}$. He became disenchanted early on because DAMA appeared to be focusing on larger companies. Seemed like Govt. was throwing a bone to the industry while scuttling it by implementing NAFTA.

2. VA is a Privately held corporation founded in 1971 by Tom's father

3. Specializes in private label manufacturing; sells packaged product to catalog retailers 
- VA makes turnkey patterns, buys all materials, cuts, makes, launders, and wrinkle-frees fabrics

- Customers provide sketches with some details

- Handles woven fabrics only; knits and fleece require different equipment

- focus on quality

4. Customers source fabrics themselves

5. 3-5 years ago, emphasis from customers was on value - what is customer getting for the money. Priorities were 1. quality, 2. service, 3. on-time delivery, 4. price. Now, priorities are 1 . price, 2 . quality, 3 . service, 4 . on-time delivery.

6. L.L. Bean says that now quality has a price component.

7. Quality of garment manufacturers in Mexico is getting better, but wages there are not increasing.

8. VA's average hourly wage is $\sim \$ 8 /$ hour; difficult to find workers interested in sewing.

9. US manufacturers must pay wages based on local/regional market forces

10. Spent $\$ 100 \mathrm{~K}$ in equipment, ongoing \$200/month w/Advantis for EDI. They send work in process info to Lands' End. Took 6-7 months to hammer out content of buy plan info exchange

11. VA wants to sell Back Creek globally, is looking for assistance with finding an easy way to do this

12. Doesn't have capital to develop new markets; requires hiring someone.

13. Lands' End and L.L. Bean want suppliers to be global to avoid shipping costs in their new global markets. Lands' End is opening new DCs in Australia, Japan, UK.

14. Most of Lands' End's products are made in US, but are drifting offshore.

15. VA recently lost major business from Lands' End and L.L. Bean offshore.

16. NAFTA accelerated movement of production to offshore.

17. Bottom line issue is cost to make a product.

18. Has instituted motion-based system of job complexity evaluation and compensation which is less subjective than before. Has resulted in some reduction in wage expense (no layoffs) and has achieved 15-30\% improvement in thruput. 


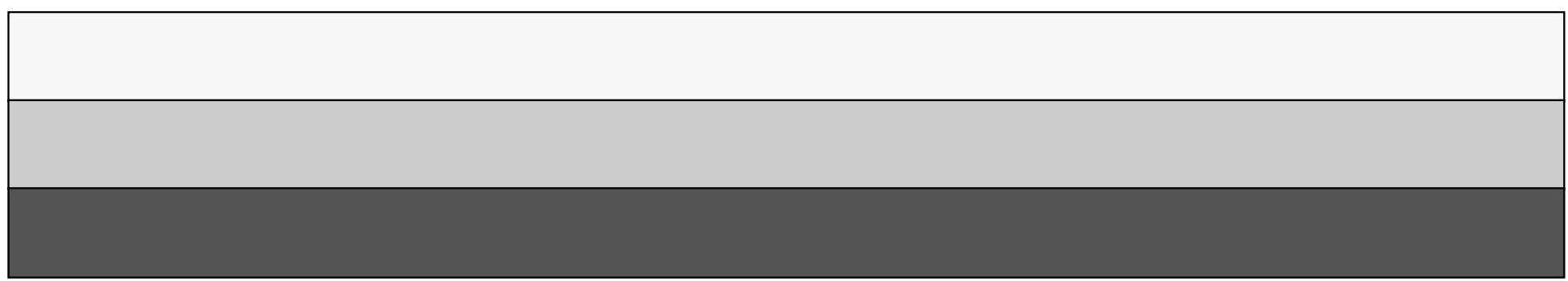

